\title{
Performance Analysis of Electronics Cooling using Nanofluids in Microchannel Heat Sink
}

\author{
Siti Natasha Malik Fesal ${ }^{1}$, SitiSyazwaniIlmin ${ }^{2}$, ZurainiGani ${ }^{3}$ \\ ${ }^{1}$ Mechanical Engineering Department, ${ }^{2}$ Mathemathics Science and Computer Department, \\ Polytechnic Ungku Omar, Ipoh, 31400, Perak, Malaysia \\ ${ }^{3}$ Mechanical Engineering Department,UniversitiKebangsaan Malaysia, 43600Bangi.Malaysia. \\ ${ }^{1}$ snatasha@puo.edu.my \\ 2ssyazwani@puo.edu.my \\ 3zyreena@yahoo.com
}

\begin{abstract}
Performance analysis of thermal enhancement for cooled microchannel heat sink (MCHS) using nanofluidsmathematical formulation was investigated and presented in this paper. Heat transfer capability in terms of thermal conductivity, heat transfer coefficient, thermal resistance, heat flux and required pumping power were evaluated on the effectiveness of copper oxide $(\mathrm{CuO})$, silicon dioxide $\left(\mathrm{SiO}_{2}\right)$ and titanium dioxide $\left(\mathrm{TiO}_{2}\right)$ with water as a base fluid. The results showed that thermal performance augmented by $\mathbf{1 2 . 2 \%}$ in thermal conductivity at particle volume fraction of $4 \%$ to $\mathrm{CuO}$-water nanofluid, $\mathbf{1 1 . 8 \%}$ for $\mathrm{SiO}_{2}$-water and $\mathbf{1 0 . 0} \%$ for $\mathrm{TiO}_{2}$-water. The maximum heat transfer coefficient enhances of $12.4 \%$ for $\mathrm{CuO}, \mathrm{SiO}_{2}$ is $8.22 \%$ and $7.4 \%$ for $\mathrm{TiO}_{2}$ with the same inlet velocity of $3 \mathrm{~m} / \mathrm{s}$. The addition of nanoparticle concentration significantly enhances the heat transfer, but elevates the expenses of higher required pumping power to increase the pressure drop. The maximum enhancement of heat flux in $\mathrm{CuO}$ water was found to be $2575 \mathrm{~kW} / \mathrm{m}^{2}, 2501 \mathrm{~kW} / \mathrm{m}^{2}$ for $\mathrm{SiO}_{2}$-water and $2485 \mathrm{~kW} / \mathrm{m}^{2}$ for $\mathrm{TiO}_{2}-\mathrm{water}^{2}$ nanofluid at $4 \%$ of volume fraction. The pressure drop is increased with the mass flow rate $\mathrm{of} 1021 \mathrm{~kg} / \mathrm{m3}$ for $\mathrm{CuO}$-water at $0.5 \%$ of volume fraction and $47925 \mathrm{~Pa}$ to $54314 \mathrm{~Pa}$ pressure drop at $4 \%$ of volume fraction. The $\mathrm{CuO}$-water pumping power was found to be the highest at $4 \%$ of volume fraction with 102.3 $\mathrm{W}$ at $3 \mathrm{~m} / \mathrm{s}$ inlet velocity compared to $\mathrm{SiO}_{2}$ and $\mathrm{TiO}_{2}$ also increased the pumping power of $75.0 \mathrm{~W}$ to 90.6 $W$ with increasing volume fraction and pressure drop. The positive thermal results implied that CuOnanofluid is a potential candidate for future applications in MCHS.Further analysis is recommended to be done with various Reynolds number, pumping power and flow rate of nanoparticles to obtain better heat transfer performance of cooling fluids.
\end{abstract}

Keywords: Electronics cooling, nanofluids, microchannel heatsink

\section{INTRODUCTION}

In the last three decades, the emergence of nanotechnologyis rapidly approaching, were utilized to improve the heat transfer rate to apply on the electronicdevices in order to reach a satisfactory level of thermal efficiency. The heat transfer rate can passively be improved by changing the geometry's flow, boundary conditions or by improving thermo physical properties such as increasing the thermal conductivity of fluid [1]. To meet the high dissipation rate requirements and maintain a low junction temperature in electronic devices, many cooling technologies have been pursued. Among of these, the microchannel heat sink (MCHS) was introduced because of its ability to produce high heat transfer coefficient, small size and volume per heat load and small coolant requirements [2].

Working fluids was applied to enhance the heat transfer by changing the fluid transport properties and flow features in MCHS. Recently, this concept has focused on heat transfer enhancement by using a nanofluid that has a nanoscale metallic or non-metallic particles in the base fluids.Besides, nanofluids has become a concern because they display higher potential as heat transfer fluid than normally utilized base fluids and micron sized particle-fluids. This is due to clogging in pumping and flow apparatus which is caused by rapid settling of the micron sized particle. Nanofluids do not indicate this behavior. This makes nanofluids a better choice as heat transfer fluid [3]. Nanofluids (1-100nm-size particles), often called as ultra-fine solid particles, engineered colloidal suspension, are stable and prepared by dispersing a certain percentage of nanoparticles in base fluids[4-6].

The factors that causes heat transfer enhancement are solid particles and host fluids chemical composition, size, shape and concentration of nanoscale particles, thermal condition and surfactants. Some of these factors also affect the stability of the nanofluids. There are three strategies to attain good stability, namely addition of surfactants, $\mathrm{pH}$ control and ultrasonification [7]. From the literature, heat transfer coefficient depends on Reynolds number, volume fraction of the nanofluids (concentration), temperature, base-fluid 
thermal properties and nanofluids purity. Generally, nanofluids are highly potential to be used as coolant in electronic packaging since their heat transfer coefficient exceeded the predicted value in laminar flow region in many analyses and from the famous Dittus-Boelter correlation in turbulent correlations [8].

Zakaria et al.[9] has studied on numerical analysis of thermal enhancement for a single Proton Exchange Membrane Fuel Cell (PEMFC) cooling plate by using a low concentration of $\mathrm{Al}_{2} \mathrm{O}_{3}$ in WaterEthylene Glycol mixtures as a coolant. It shown that the higher volume percent concentration of $\mathrm{Al}_{2} \mathrm{O}_{3}$ the better the heat transfer enhancement but at the higher expense of pumping power.

Moraveji et al. [10] used a model of MCHS with 20 × $20 \mathrm{~mm}$ bottom with five nanoparticle volume fractions in five inlet velocities for two types of nanoparticle containing $\mathrm{TiO}_{2}$ and SiC.By using different value of Reynolds Numbers, the effect of a nanoparticle volume fraction on the convective heat transfer coefficient was investigated. The modelling results was compared to analytical calculations and it showed that, it was accurate for the correlated equations that were obtained for Nusselt number and friction factor were acceptable.

The numerical simulations is studied on the laminar and turbulent forced convection heat transfer in a MCHS with a mixture of nanofluid consisting of CuO-water [11]. The method used to solve the continuity, momentum and energy equations was the finite volume method with the parameters of the particle volume faction $(\phi=0.204 \%, 0.256 \%, 0.294 \%$ and $0.4 \%)$, and the volumetric flow rate $(\dot{V}=10 \mathrm{~mL} / \mathrm{min}, 15 \mathrm{~mL} / \mathrm{min}$ and $20 \mathrm{~mL} / \mathrm{min}$ ). From the comparisons of thermal resistance predicted by the single-phase and two-phase models with the experimental results, it revealed that, two-phase model was more accurate than the single-phase model. Other than that, the thermal resistance of nanofluids is smaller than that of water, which decreases as the particle volume fraction and the volumetric flow rate increase in laminar flow. In addition, the pressure drop increases slightly for nanofluid-cooled MCHS in the laminar flow case.

This study deals with three types of nanoparticles which are copper oxide(CuO), silica( $\left(\mathrm{SiO}_{2}\right)$ and titanium oxide $\left(\mathrm{TiO}_{2}\right.$ ) suspended in a water as a base fluid. The microchannel heat sink (MCHS) operation was analyzed with the nanofluids serve as a working fluid.Performance of nanofluids as coolant is predicted in terms of thermal conductivity, heat transfer coefficient, thermal resistance, heat flux and required pumping power.

\section{METHODOLOGY}

The performance of $\mathrm{CuO}$-water, $\mathrm{SiO}_{2}$-water and $\mathrm{TiO}_{2}$-water nanofluids has been analyzed by using mathematical formulation to compare the performance of cooling of electronics. Thermophysical properties of the water and nanoparticles $\left(\mathrm{CuO}, \mathrm{SiO}_{2}, \mathrm{TiO}_{2}\right)$ at $30^{\circ} \mathrm{C}$ areas shownin Table I.

TABLE I. Thermophysical properties of the base fluid and nanoparticles $[10,12]$

\begin{tabular}{|l|c|c|c|c|}
\hline \multirow{2}{*}{ Fluid/Nanoparticles } & \multicolumn{4}{|c|}{ Properties } \\
\cline { 2 - 5 } & $\boldsymbol{\rho ( \mathbf { k g } / \mathbf { m } 3 )}$ & $\boldsymbol{\mu ( N . s / m 3 )}$ & $\mathbf{C p}(\mathbf{J} / \mathbf{k g . K})$ & $\mathbf{k}(\mathbf{W} / \mathbf{m} . \mathbf{K})$ \\
\hline Base Water, $\mathrm{H}_{2} \mathrm{O}$ & 994.2 & $724.6 \times 10-6$ & 4178 & 0.6248 \\
\hline Copper Oxide, $\mathrm{CuO}$ & 6320 & - & 385 & 76.5 \\
\hline Silica Dioxide, $\mathrm{SiO}_{2}$ & 3970 & - & 765 & 36 \\
\hline Titanium Dioxide, $\mathrm{TiO}_{2}$ & 4157 & - & 710 & 8.4 \\
\hline
\end{tabular}

\section{A. Nanofluid Properties}

The thermophysical properties of the nanofluidswiththe volume fractions, $\phi$, of nanoparticles and base fluid were used; $0.5 \%, 1.0 \%, 1.5 \%, 2.0 \%, 2.5 \%, 3.0 \%, 3.5 \%$ and $4.0 \%$ are determined by utilizing the following equations:

Density of nanofluid is calculated by the use of Pak and Cho [13]correlation:

$\rho_{n f}=\varnothing \rho_{s}+(1-\emptyset) \rho$

Effective thermal conductivity is given by Hamilton and Crosser [13] equation, can be expressed as follow:

$k_{n f}=\frac{k_{p}+(n-1) k_{f}-(n-1) \emptyset\left(k_{f}-k_{p}\right)}{k_{p}+(n-1) k_{f}+\emptyset\left(k_{f}-k_{p}\right)} k_{f}$

Nanofluid specific heat equation is evaluated from Xuan andRoetzelcorrelation [14] which shown below:

$\left(\rho C_{p}\right)_{n f}=(1-\emptyset)\left(\rho C_{p}\right)_{f}+\emptyset\left(\rho C_{p}\right)_{p}$

Effective viscosity of nanofluid is given by Einstein equation as suggested for particle in volume fractions less than $5.0 \mathrm{vol} . \%$ and is defined [15]: 
$\mu_{n f}=\mu(1+2.5 \emptyset)$

Where subscript $f, p, n f$ are correspond to fluid, particle and nanofluids respectively. Nanoparticle shape factor, $n$, was assumed to be 3 for spherical particles as tabulated in Table II.

TABLE II. Calculated thermophysical properties for nanofluids

\begin{tabular}{|c|c|c|c|c|}
\hline \multicolumn{5}{|c|}{$\mathbf{C u O} /$ Water Properties } \\
\hline Particle Volume Fraction $(\boldsymbol{\varnothing} \%)$ & $\mathbf{\rho C u O}$ & $\mathbf{k C u O}$ & $\mathbf{\rho C p C u O}$ & $\boldsymbol{\mu C u O}$ \\
\hline $0.5 \%$ & 1020.83 & 0.63399 & 4145165 & 0.00073 \\
\hline $1.0 \%$ & 1047.46 & 0.64327 & 4136562 & 0.00074 \\
\hline $1.5 \%$ & 1074.09 & 0.65265 & 4127959 & 0.00075 \\
\hline $2.0 \%$ & 1100.72 & 0.66211 & 4119356 & 0.00076 \\
\hline $2.5 \%$ & 1127.35 & 0.67167 & 4110753 & 0.00077 \\
\hline $3.0 \%$ & 1153.97 & 0.68133 & 4102151 & 0.00078 \\
\hline $3.5 \%$ & 1180.60 & 0.69109 & 4093548 & 0.00079 \\
\hline $4.0 \%$ & 1207.23 & 0.70094 & 4084945 & 0.00080 \\
\hline
\end{tabular}

\section{$\mathrm{SiO}_{2} /$ WaterProperties}

\begin{tabular}{|c|c|c|c|c|}
\hline Particle Volume Fraction $(\boldsymbol{\phi} \%)$ & $\mathbf{\rho ~ S i O}_{\mathbf{2}}$ & $\mathbf{k ~ \mathbf { S i O } _ { 2 }}$ & $\mathbf{\rho C p S i O}_{\mathbf{2}}$ & $\boldsymbol{\mu} \mathbf{S i O}_{\mathbf{2}}$ \\
\hline $0.5 \%$ & 1009.08 & 0.63374 & 4148184 & 0.00073 \\
\hline $1.0 \%$ & 1023.96 & 0.64277 & 4142600 & 0.00074 \\
\hline $1.5 \%$ & 1038.84 & 0.65189 & 4137017 & 0.00075 \\
\hline $2.0 \%$ & 1053.72 & 0.66109 & 4131433 & 0.00076 \\
\hline $2.5 \%$ & 1068.60 & 0.67038 & 4125850 & 0.00077 \\
\hline $3.0 \%$ & 1083.47 & 0.67977 & 4120266 & 0.00078 \\
\hline $3.5 \%$ & 1098.35 & 0.68924 & 4114682 & 0.00079 \\
\hline $4.0 \%$ & 1113.23 & 0.69881 & 4109099 & 0.00080 \\
\hline
\end{tabular}

$\mathrm{TiO}_{2} /$ WaterProperties

\begin{tabular}{|c|c|c|c|c|}
\hline Particle Volume Fraction $(\varnothing \mathbf{\%})$ & $\mathbf{\rho ~ T i O}_{\mathbf{2}}$ & $\mathbf{k} \mathbf{T i O}_{\mathbf{2}}$ & $\mathbf{\rho C p T i O}_{\mathbf{2}}$ & $\boldsymbol{\mu} \mathbf{T i O}_{\mathbf{2}}$ \\
\hline $0.5 \%$ & 1010.01 & 0.63238 & 4147756 & 0.00073 \\
\hline $1.0 \%$ & 1025.83 & 0.64003 & 4141745 & 0.00074 \\
\hline $1.5 \%$ & 1041.64 & 0.64773 & 4135733 & 0.00075 \\
\hline $2.0 \%$ & 1057.46 & 0.65550 & 4129722 & 0.00076 \\
\hline $2.5 \%$ & 1073.27 & 0.66333 & 4123710 & 0.00077 \\
\hline $3.0 \%$ & 1089.08 & 0.67123 & 4117699 & 0.00078 \\
\hline $3.5 \%$ & 1104.90 & 0.67919 & 4111687 & 0.00079 \\
\hline $4.0 \%$ & 1120.71 & 0.68722 & 4105676 & 0.00080 \\
\hline
\end{tabular}




\section{B. Microchannel Heat Sink (MCHS)}

The MCHS which typically contains lot of parallel microchannel has the capability of producing high heat transfer coefficient, less dimension-volume per heat load and lesser requirement of coolant [2]. There were few assumptions have been made in order to simplify this analysis whereby[9]:

- The flow is incompressible, laminar and in steady state.

- The effect of body force is neglected.

- The fluid properties are constant and viscous dissipation is neglected.

- The fluid phaseand nanoparticles are in thermal equilibrium with zero relative velocity and the resultant mixture can be considered as a conventional single phase.

The geometric configuration of this microchannel is considered based on research of Tsai and Chein[2] shown in Fig.1 whereby the nanofluids is forced to flow through the fin slot in x-direction with mean velocities of $3 \mathrm{~m} / \mathrm{s}$. Table III below shows the details of MCHS dimensions.

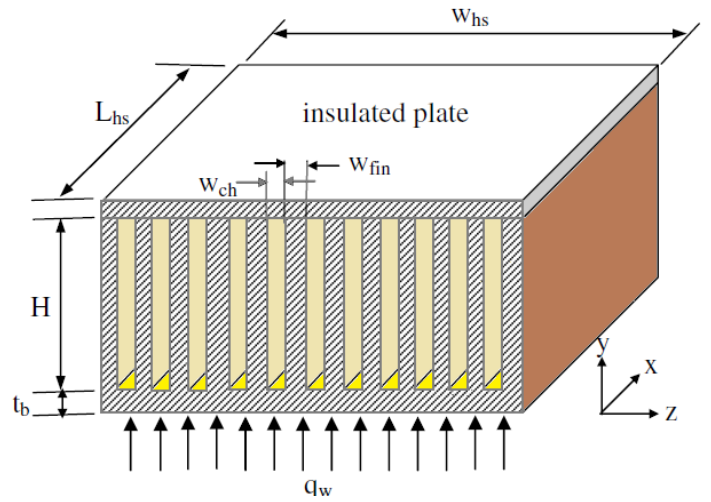

Fig. 1. MCHS schematic diagram [2]

TABLE III. Dimensions of MCHS [2]

\begin{tabular}{|l|l|}
\hline Symbol & Size \\
\hline Size $\mathrm{L}_{\mathrm{hs}} \times \mathrm{W}_{\mathrm{hs}}$ & $1 \mathrm{~cm} \times 1 \mathrm{~cm}$ \\
\hline Channel height, $\mathrm{H}$ & $365 \mu \mathrm{m}$ \\
\hline Channel width, $\mathrm{W}_{\mathrm{ch}}$ & $57 \mu \mathrm{m}$ \\
\hline Porosity, $\varepsilon$ & 0.5 \\
\hline Fin thickness, $\mathrm{W}_{\text {fin }}$ & $57 \mu \mathrm{m}$ \\
\hline Number of channels,n & 25 \\
\hline Aspect ratio, $\alpha_{s}$ & 6.4 \\
\hline
\end{tabular}


Parameters like hydraulic diameter and other dimensionless correlations for Reynolds number, Prandtl number and Nusselt number are consideredunder the assumption of single phase, constant thermal properties applicablefor laminar and turbulent flows in order to analyze the efficiency of MCHS by applying nanofluids to achieve the heat dissipation capability $[16,17]$.

The heat transfer coefficient is calculated by using:

$$
h=\frac{N u k_{n f}}{D_{h}}
$$

Where;

$\begin{array}{llll}\text { Hydraulic diameter } & : & D_{h}=\frac{4 W_{c h} H}{2\left(W_{c h}+H\right)} \\ \text { Reynolds number } & : & R e=\frac{V_{m} D_{h}}{v} \\ \text { Prandtl number } & : & P r & =\left(\frac{C_{p} \mu}{k}\right)_{n f} \\ \text { Nusselt number } & : & N u=0.023 \operatorname{Re}^{0.8} \operatorname{Pr}^{0.3}\end{array}$

The calculation for Reynolds, Prandtl and Nusselt number are based on the assumption that the fluid flow with the inlet speed of $3 \mathrm{~m} / \mathrm{s}$ for various volume fraction of nanoparticle.

The efficiency of the microchannel is computed using:

$$
\eta=\frac{\tanh (m \times H)}{(m \times H)}
$$

Where;

$$
m \times H=\sqrt{\frac{2 h}{k_{s} W_{\text {fin }}}} \times H
$$

$k_{s}$ is the MCHS thermal conductivity which is $400 \mathrm{~W} / \mathrm{mK}$.

Furthermore, total thermal resistance is computed using the summation of all the three resistances:

$$
R_{t}=\frac{1}{h A_{s}}+\frac{1}{\dot{m} C_{p}}+\frac{H}{k_{s} A_{b}}
$$

where $A_{b}$ is the area of MCHS bottom part and $\dot{m}$ is the total nanofluid mass flowrate [12].

The surface area is calculated by the formula of: $\quad \dot{m}=n \rho_{n f} A_{c}$

where $A_{c}$ is the channel area.

$$
A_{s}=n W_{c h} L_{h s}+2 n \eta H L_{h s}
$$

Number of cooling channels, $\mathrm{n}=25$ [18].

Thus, the total heat transfer $(Q)$ and the bottom heat flux $\dot{q}$ is computed using:

$$
Q=\frac{T_{\max }-T_{i}}{R_{t}}
$$

and

$$
\dot{q}=\frac{Q}{A_{b}}
$$

Where, $T_{i}$ is the fluid temperature at the inlet and $T_{\max }$ is the largest of bottom temperature of microchannels. From Xie et.al [19] the maximumdifferenceof $\left(T_{\max }-T_{i}\right)$ is taken to be $50^{\circ} \mathrm{C}$.

\section{Effectiveness Evaluation of Nanofluid for Electronics Cooling}

The effectiveness of nanofluid as coolant is evaluated in term of performance of microchannel heat sink. This analysis is crucial in order to see the impact of the viscous pressure drop on the performance of MCHS.

Coefficient of performance, COP for MCHS is defined as the ratio of the dissipated heat to the invested pumping power [20].

$$
C O P=\frac{Q}{P}
$$

Where;

$$
\begin{aligned}
& \text { Ppow }=\dot{V} \Delta p \\
& \dot{V}=n \rho_{n f} W_{c h} H V_{m}
\end{aligned}
$$

(Ppow: Idealized pumping power and: Volumetric flowrate of nanofluid, n: Number of channels).

The pressure drop is calculated using [21],

$$
\Delta p=f \frac{L_{h s} \rho V_{m}^{2}}{D_{h}{ }^{2}}
$$


with Darcy friction factor : $f=(1.82 \log R e-1.64)^{-2}$

\section{RESULT AND DISCUSSION}

Nanoparticle addition in fluid base will result higher thermal conductivity compared to a conventional liquid and conventional two-phase mixture coolant. Solid particle are added as they conduct heat much better than a liquid on its own. In this study, three types of nanofluids were used as coolant in microchannel heat sink. Performance of nanofluids as coolant were predicted in terms of thermal conductivity, heat transfer coefficient, thermal resistance, heat flux and required pumping power. The result was compared with conventional liquid which is water. Table IV shows the properties of water as coolant in MCHS with inlet velocity of $3 \mathrm{~m} / \mathrm{s}$.

TABLE IV. Properties of water in MCHS with inlet velocity of 3 m/s.

\begin{tabular}{|l|c|}
\hline Properties & Values \\
\hline Thermal conductivity, $k(\mathrm{~W} / \mathrm{m} . \mathrm{K})$ & 0.6248 \\
\hline Heat transfer coefficient, $h\left(\mathrm{~W} / \mathrm{m}^{2} . \mathrm{K}\right)$ & 30111.41 \\
\hline Reynolds No, Re & 405.87 \\
\hline Prandtl No, $\mathrm{Pr}$ & 4.85 \\
\hline Nusselt No, Nu & 4.75 \\
\hline
\end{tabular}

The prediction of performance of $\mathrm{CuO}$-water, $\mathrm{SiO}$-water and $\mathrm{TiO}_{2}$-water nanofluids were calculated using Eq. (1)-Eq (21). The calculated data is shown in Table V, Table VI and Table VII.

TABLE V. Thermal conductivity, heat transfer coefficient and mass flow rate of CuO-water nanofluid.

\begin{tabular}{|c|c|c|c|}
\hline \multicolumn{4}{|c|}{$\mathbf{C u O} /$ Water } \\
\hline Particle Volume Fraction $(\boldsymbol{\varnothing} \%)$ & $\mathbf{k}(\mathbf{W} / \mathbf{m} \cdot \mathbf{K})$ & $\mathbf{h}\left(\mathbf{W} / \mathbf{m}^{2} \cdot \mathbf{K}\right)$ & $\dot{\mathbf{m}}(\mathbf{k g} / \mathbf{s})$ \\
\hline $0.5 \%$ & 0.63399 & 30584 & 0.01455 \\
\hline $1.0 \%$ & 0.64327 & 31055 & 0.01493 \\
\hline $1.5 \%$ & 0.65265 & 31525 & 0.01531 \\
\hline $2.0 \%$ & 0.66211 & 31993 & 0.01569 \\
\hline $2.5 \%$ & 0.67167 & 32460 & 0.01606 \\
\hline $3.0 \%$ & 0.68133 & 32926 & 0.01644 \\
\hline $3.5 \%$ & 0.69109 & 33392 & 0.01682 \\
\hline $4.0 \%$ & 0.70094 & 33856 & 0.01720 \\
\hline
\end{tabular}

TABLE VI. Thermal conductivity, heat transfer coefficient and mass flow rate of $\mathrm{SiO}_{2}$-water nanofluid.

\begin{tabular}{|c|c|c|c|}
\hline \multicolumn{4}{|c|}{$\mathbf{S i O}_{2} /$ Water } \\
\hline Particle Volume Fraction( $\varnothing$ \%) & $\mathbf{k}(\mathbf{W} / \mathbf{m} . \mathbf{K})$ & $\mathbf{h}(\mathbf{W} / \mathbf{m} 2 . \mathbf{K})$ & $\dot{\mathbf{m}}(\mathbf{k g} / \mathbf{s})$ \\
\hline $0.50 \%$ & 0.63374 & 30419 & 0.01438 \\
\hline $1.00 \%$ & 0.64277 & 30727 & 0.01459 \\
\hline $1.50 \%$ & 0.65189 & 31037 & 0.01480 \\
\hline $2.00 \%$ & 0.66109 & 31347 & 0.01502 \\
\hline $2.50 \%$ & 0.67038 & 31658 & 0.01523 \\
\hline $3.00 \%$ & 0.67977 & 31970 & 0.01544 \\
\hline $3.50 \%$ & 0.68924 & 32283 & 0.01565 \\
\hline $4.00 \%$ & 0.69881 & 32597 & 0.01586 \\
\hline
\end{tabular}


TABLE VII. Thermal conductivity, heat transfer coefficient and mass flow rate of $\mathrm{TiO}_{2}$-water nanofluid.

\begin{tabular}{|c|c|c|c|}
\hline \multicolumn{4}{|c|}{$\mathrm{TiO}_{2} /$ Water } \\
\hline Particle Volume Fraction $\varnothing$ \%) & $\mathbf{k}(\mathbf{W} / \mathbf{m} . \mathbf{K})$ & $\mathbf{h}(\mathbf{W} / \mathbf{m} 2 . K)$ & $\mathbf{m} \mathbf{( k g / s )}$ \\
\hline $0.50 \%$ & 0.63238 & 30387 & 0.01439 \\
\hline $1.00 \%$ & 0.64003 & 30664 & 0.01462 \\
\hline $1.50 \%$ & 0.64773 & 30940 & 0.01484 \\
\hline $2.00 \%$ & 0.65550 & 31217 & 0.01507 \\
\hline $2.50 \%$ & 0.66333 & 31494 & 0.01529 \\
\hline $3.00 \%$ & 0.67123 & 31772 & 0.01552 \\
\hline $3.50 \%$ & 0.67919 & 32050 & 0.01574 \\
\hline $4.00 \%$ & 0.68722 & 32328 & 0.01597 \\
\hline
\end{tabular}

\section{A. Thermal Conductivity of nanofluids}

Thermal conductivity enhancement as a function of particle volume fraction for the CuO-water, SiO2-water and $\mathrm{TiO} 2$-water nanofluids was obtained using Hamilton and Crosser static analysis method from Eq. (2). The plotted results show the thermal conductivity linearly increases as the particle volume fraction increases as seen in Fig.2. The difference in thermal conductivity enhancement increases with the increased particle volume fraction, and is as large as $12.2 \%$ at particle volume fraction of $4 \%$ for $\mathrm{CuO}$-water, followed by $11.8 \%$ for SiO2water and finally $10.0 \%$ for TiO2-water nanofluids. The highest thermal conductivity was about 0.70094 W/m.K for CuO-water, $0.69882 \mathrm{~W} / \mathrm{m} . \mathrm{K}$ for SiO2-water and $0.68722 \mathrm{~W} / \mathrm{m} . \mathrm{K}$ for TiO2-water nanofluids as shown in Table V, Table VI and Table VII for inlet velocity of $3 \mathrm{~m} / \mathrm{s}$. The increment of CuO-water nanofluidascompared to other nanofluids is due to large particle-liquid interfacial area thus exhibited higher heat transfer rate, which directly indicated the high thermal conductivity contained within the nanoparticles. The enhancement mechanism may be due to the addition of these nanoparticles to the base fluid (water) which has higher thermal conductivity compare to the base fluid led to improve thermal conductivity of the nanofluid. These results also comparable with other studies done by researchers using different nanofluids.

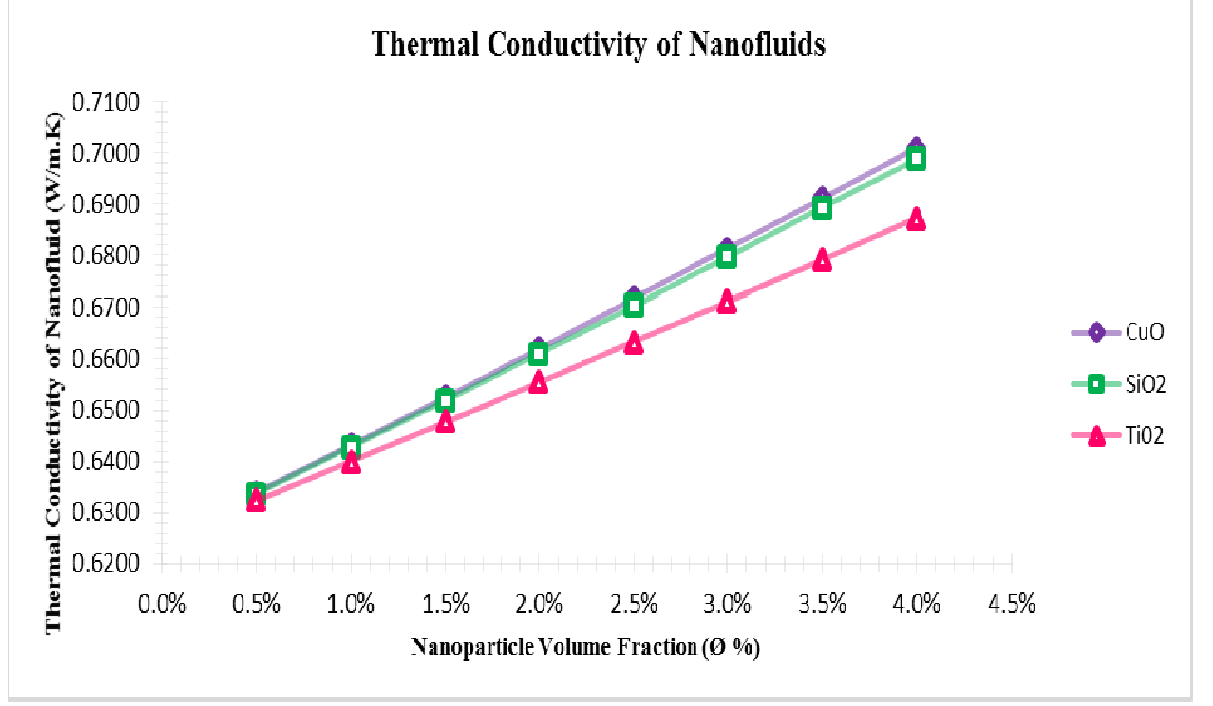

Fig 2: Increasing thermal conductivity nanofluids with particle volume fraction

\section{B. Heat Transfer Coefficient of nanofluids to MCHS}

The thermal performances of the nanofluids depend on the convective heat transfer coefficient. The increasing effects of the nanofluid concentrations promotes the heat transfer coefficient as shown in Fig. 3a). The heat transfer coefficient was calculated and expected to increase if thermal conductivity increases for all the coolants using Eq. (5). Fig. 3a) exhibits that there is an effective enhancement of the heat transfer coefficient in the range of Reynolds number from 400 and also with increasing of volume fraction from 0.5 to 4.0 vol.\%. At the highest volume fraction, $\mathrm{CuO}$-water nanofluid provided around $12.4 \%$ higher value of convective heat transfer coefficient with the comparison of the SiO2-water and $\mathrm{TiO}$-water nanofluid which found $8.22 \%$ and $7.4 \%$ respectively for the same inlet velocity of $3 \mathrm{~m} / \mathrm{s}$. Also heat transfer coefficient of CuO-water $\mathrm{SiO2}$-water 
and TiO2-water were $33847 \mathrm{~W} / \mathrm{m} 2 . \mathrm{K}, 32589 \mathrm{~W} / \mathrm{m} 2 . \mathrm{K}$ and $32328 \mathrm{~W} / \mathrm{m} 2 . \mathrm{K}$, correspondingly at $4 \%$ volume percentage at the same $3.0 \mathrm{~m} / \mathrm{s}$ inlet velocity. On the other hand, the heat transfer coefficient is also influenced by inlet velocity of the coolant and is a function of Reynolds number .With the increasing of nanofluid velocity, it will increase the nanoparticles movement or inter-collision which effectively enhances the heat transfer rate. So, the significant increase in Nusselt number and Reynolds numbers encourage the useofCuO-water nanofluid as a better coolant instead of a conventional coolant.

Addition of nanoparticles in liquid remarkably enhances energy transport process of the base liquid due to the chaotic movement of nanoparticles in the main flow. Increasing of volume fraction of nanoparticles will increase the density of nanofluids and lead to an increase in the mass flow rate. From Eq.(5) it shows that heat transfer coefficient increases with increasing thermal conductivity in conjunction of increasing volume fraction of nanoparticles. For example, CuO-water nanofluid at $0.5 \%$ volume fraction has mass flow rate of $0.015 \mathrm{~kg} / \mathrm{s}$ and $30576 \mathrm{~W} / \mathrm{m}^{2} . \mathrm{K}$ heat transfer coefficient with $3 \mathrm{~m} / \mathrm{s}$. At $4 \%$ volume fraction, the mass flow rate for CuOwater nanofluid is $0.017 \mathrm{~kg} / \mathrm{s}$ and $33847.41 \mathrm{~W} / \mathrm{m}^{2} . \mathrm{K}$ heat transfer coefficient with same inlet velocity as shown in Fig.3b).

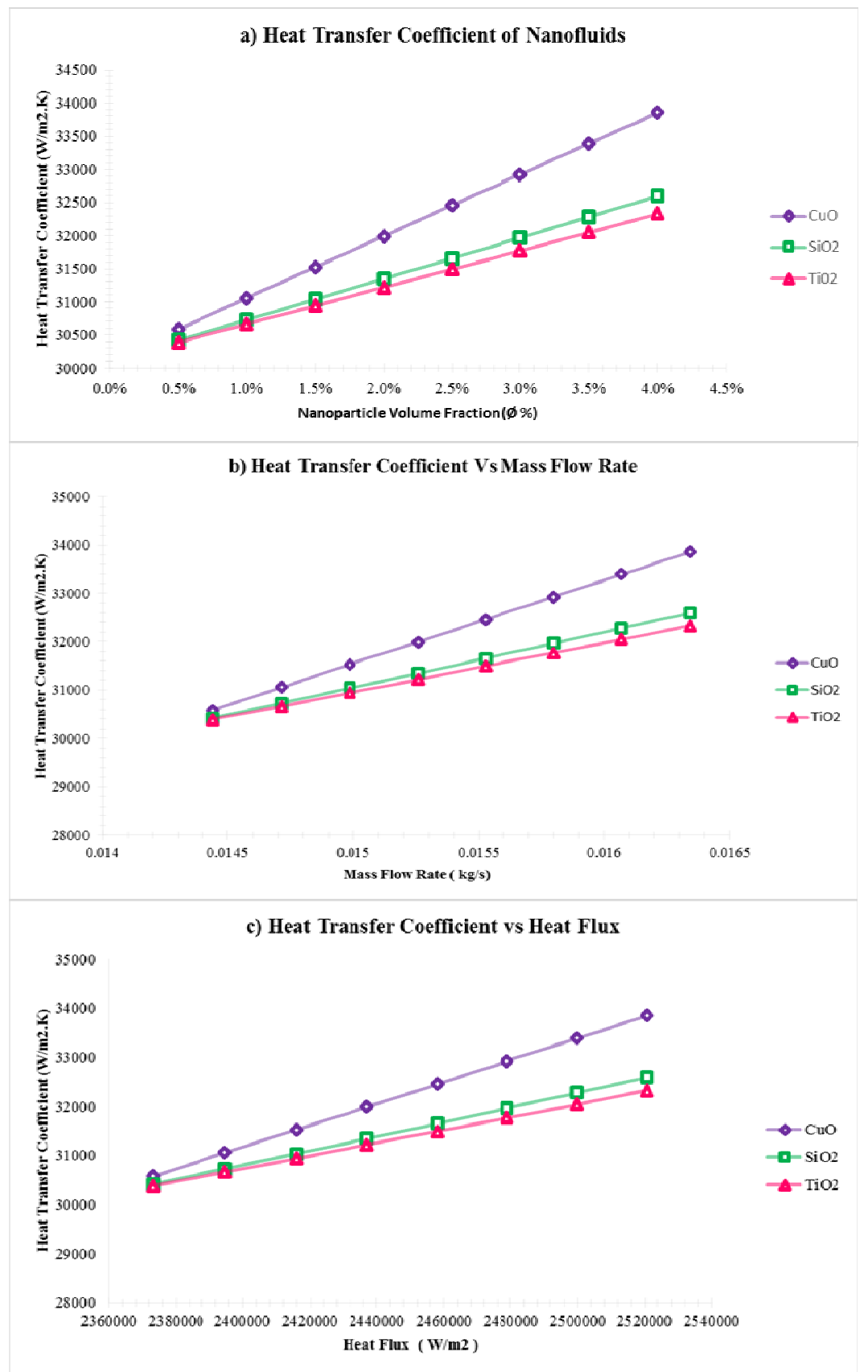

Fig 3a): Increasing heat transfer coefficient with particle volume fraction .Fig3b) Increasing heat transfer coefficient as function of mass flow rate Fig 3c) Increasing heat transfer coefficient with heat flux. 
High heat flux removal is crucial for electronic devices. From this study, it was found that the heat flux increases for all typesnanofluids with increasing volume fraction of nanoparticles. The maximum enhancement of heat flux in CuO-water was found to be $2575 \mathrm{~kW} / \mathrm{m}^{2}$, followed by SiO2-water for $2501 \mathrm{~kW} / \mathrm{m}^{2}$ and $2485 \mathrm{~kW} / \mathrm{m}^{2}$ for $\mathrm{TiO}_{2}$-water nanofluid at $4 \%$ of volume fraction. Water has been used as a single-phase coolant however its thermal conductivity is lower than most metal and metal oxide. Since metal and metal oxide has higher thermal conductivity, the addition of metal or metal oxide nanoparticle in base-fluid or water can increases the thermal conductivity of the coolant which led to a decrease in thermal resistance and give high heat flux as shown in Fig.3c).

\section{C.Thermal Resistance of nanofluids}

Thermal resistances are the functions of many parameters such as heat transfer coefficient, h, area of $\mathrm{MCSH}$, mass flow rate of the nanofluid, thermal conductivity, $\mathrm{k}$, and channel depth, $\mathrm{H}$. By using Eq. (12) it is found that the increasing the volume concentration of the nanoparticle shows a declining trend to diminish the convective thermal resistance and thermal dispersion for all coolants and consistently can be seen at Fig. 4 . Fig. 4 represents the diversity of the convective thermal resistance with the disparity of the volume concentration of the $\mathrm{CuO}$-water, $\mathrm{SiO} 2-$-water and $\mathrm{TiO} 2-$ water nanofluid in the range of Reynolds number of 400 . Thus, enhancing in convective heat transfer coefficient ultimately decreases the thermal resistance of the nanofluid.

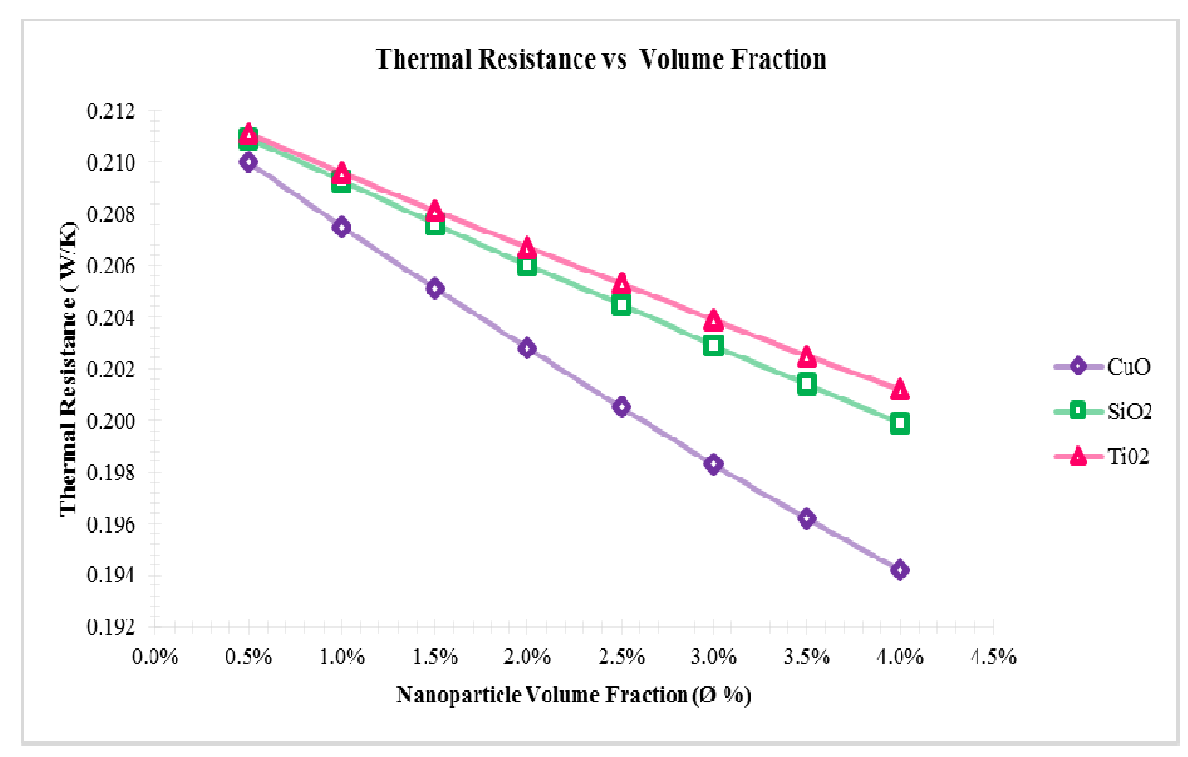

Fig.4: Decreasing thermal resistance with increasing particle volume fraction

\section{Pumping Power}

Another important parameter in the MCHS operation is the pressure drop which relates to the required coolant pumping power. Parameters that influenced the pressure drop are channel width Wc, channel height Hc, bottom thickness Ww, and inlet velocity Vm .Using Eq. (20), the predicted results for pressure drops was obtained for all types of nanofluids are shown in Figure 7. 


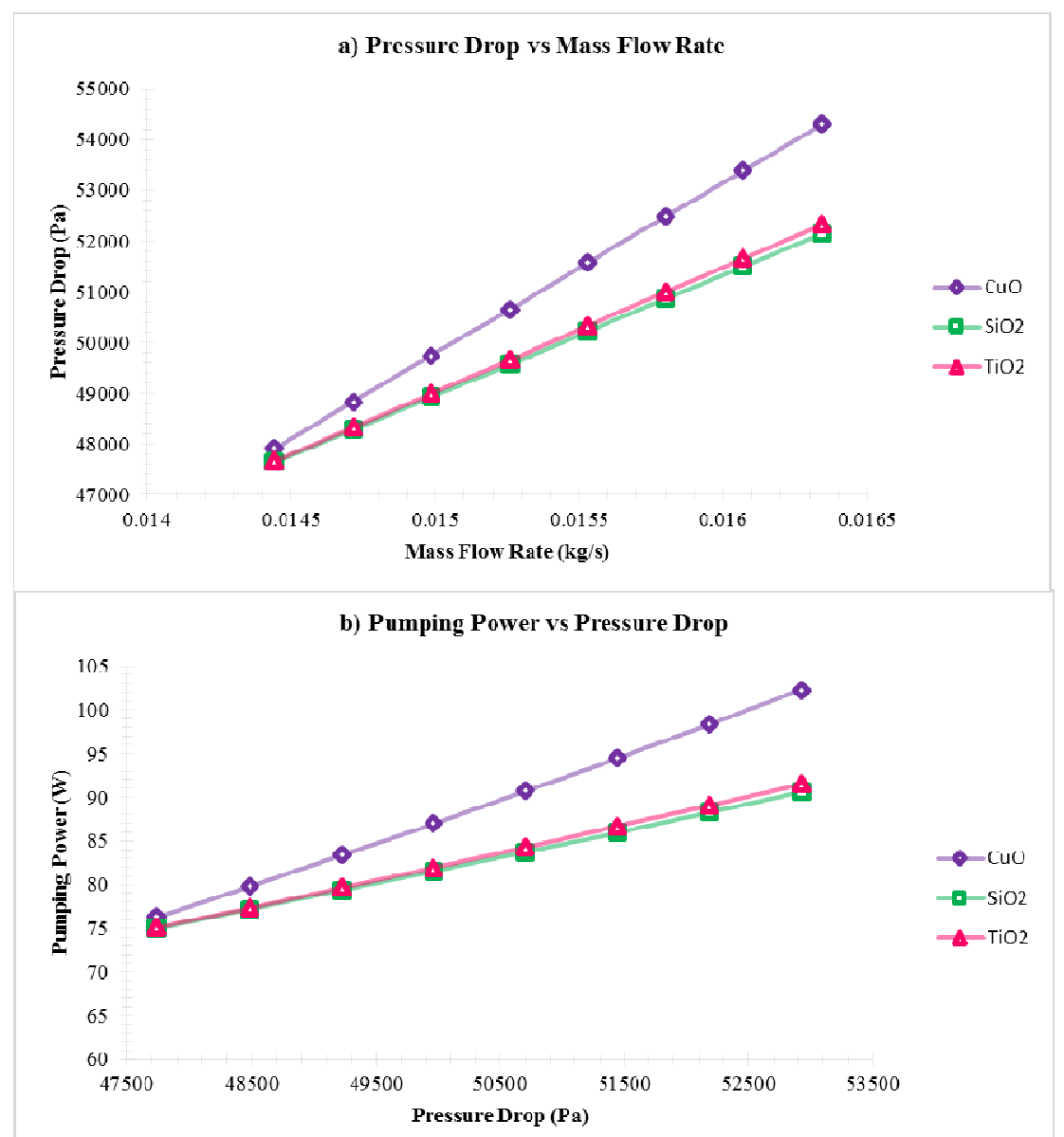

Fig.7: a): Increasing pressure drop with mass flow rate at $3 \mathrm{~m} / \mathrm{s}$ inlet velocity.b): Pressure drop with pumping power at $3 \mathrm{~m} / \mathrm{s}$ inlet velocity.

Fig.7a) demonstrates the increasing linearly in pressure drop as the mass flow rate augmented as well as the volume percentage for all types of nanofluids. From the result, it shows that CuO-water has a density of $1021 \mathrm{~kg} / \mathrm{m}^{3}$ at $0.5 \%$ of volume fraction and $47925 \mathrm{~Pa}$ pressure drop. The pressure drop increases linearly with increasing volume fraction with maximum pressure drop of $54314 \mathrm{~Pa}$ at $4 \%$ of volume fraction at $3 \mathrm{~m} / \mathrm{s}$. Since the viscosity of nanofluid is larger than the pure fluid, a larger pressure drop is expected as well as the pumping power required in the nanofluids MCHS operation. From Eq. (18), it can be interpreted that pumping power directly proportional to pressure drop thus when pressure drop increases the pumping power increases as well. The pumping power also depends on the nanofluid concentration. Due to the higherdensity and viscosity of nanofluids,it has causedmore power needed to drive the coolant passes through the narrow channel of the heat sink. The pumping power for $\mathrm{CuO}$-water was found to be highest at $4 \%$ of volume fraction with $102.3 \mathrm{~W}$ at 3 $\mathrm{m} / \mathrm{s}$ inlet velocity. The observed trending also applies to $\mathrm{SiO}_{2}$ and $\mathrm{TiO}_{2}$ where the pumping power increases from $75.0 \mathrm{~W}$ up to $90.6 \mathrm{~W}$ with increasing volume fraction and pressure drop. Fig.7b) shows the relationship between pumping power with pressure drop for all types of nanofluid.This result promotes that the pressure drop directly dependence on the higher density and viscosity of nanofluid to raise the pumping power of the nanofluid. 


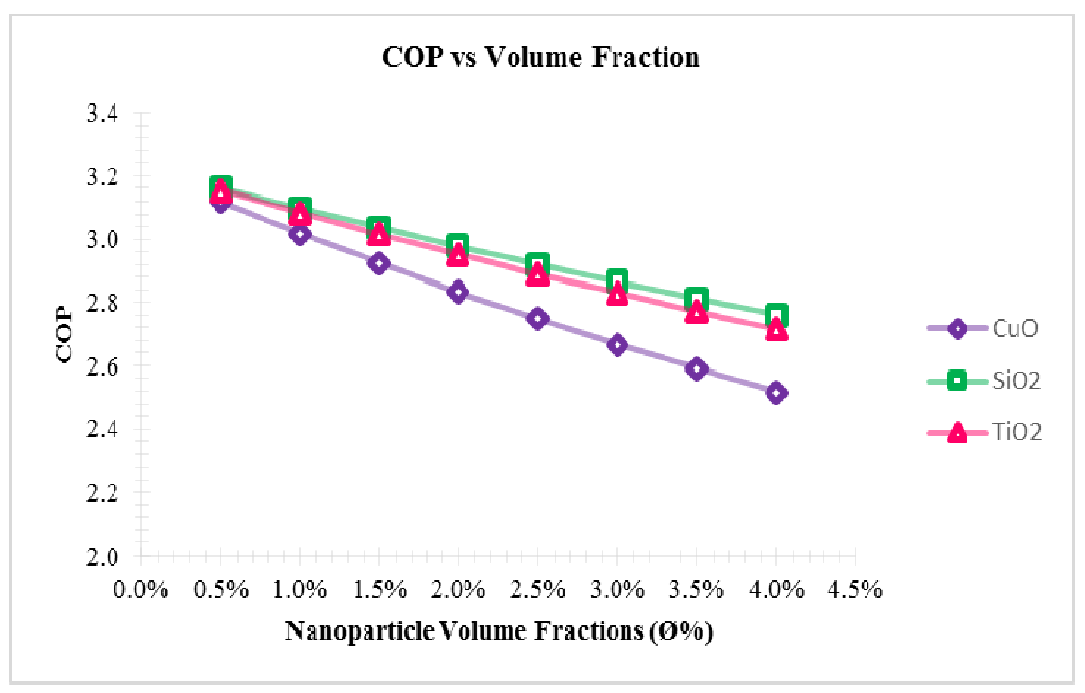

Fig.8: COP with nanoparticle volume fractions.

In order to measure efficiency of nanofluids as coolant for electronic devices, it is crucial to calculate the coefficient of performance of the MCHS. This analysis shows the impact of volume fraction to the performance of MCHS as thermophysical properties of nanofluid changed with addition of nanoparticle. Fig. 9 shows that COP decreases with the increasing volume fraction nanoparticles for all typesofnanofluids.

\section{IV.CONCLUSION}

This study analysed the thermal performance of rectangular MCHS using copper oxide (CuO)/water, silica dioxide $\left(\mathrm{SiO}_{2}\right)$ /water and titanium dioxide $\left(\mathrm{TiO}_{2}\right)$ /water nanofluids at different volume fraction with constant inlet velocity. Mathematical formulation were used to compare their heat transfer capability in terms of thermal conductivity, heat transfer coefficient, thermal resistance, heat flux and required pumping power. Results confirmed that at higher particle volume fraction the $\mathrm{CuO}$-water nanofluid has significant enhancement in thermal performances for electronics cooling compared to $\mathrm{SiO}_{2}$-water and $\mathrm{TiO}_{2}$-water nanofluid. Thus $\mathrm{CuO}$ could be proposed as potential substitutes for conventional coolants in laminar flow conditions especially in micro-scale equipments. The results revealed that there is considerable increase in conductivity and viscosity with the increase of particle volume fraction of nanofluids.For heat transfer coefficient, it was influenced by fluid velocity entrance effects and as function of Reynolds number. The pressure drop increases linearly with the increase of volume fraction and it is affected the amount of pumping power. High concentration of pumping power is required to move the coolant. The volume fraction of nanofluids, give impact to the performance of heat transfer by reducing the thermal resistance of MCHS and show a good agreement with the past experimental analysis.

\section{ACKNOWLEDGEMENT}

The authors would like to acknowledge Polytechnic Ungku Omar, UniversitiKebangsaan Malaysia, Ministry of Higher Education of Malaysia and UniversitiTun Hussein Onn,BtPahat,Malaysia for their support and assistance given to the authors in carrying out this research study.

\section{REFERENCES}

[1] R. Davarnejad and R. M. Ardehali, "Modeling of TiO2-water Nanofluid Effect on Heat Transer and Pressure Drop,” IJE Transactions B: Applications, vol. 27, no.2, pp. 195-202, Feb. 2014.

[2] T.S. Tsai and R. Chein, "Performance analysis of nanofluid-cooled microchannel heat sinks," International Journal of Heat and Fluid Flow, vol. 28, pp. 1013-1026, Mar. 2007.

[3] N. A. Roberts, and D.G. Walker, "Convective performance of nanofluids in commercial electronics cooling systes," Applied thermal engineering, vol. 30(16), pp. 2499-2504, 2010.

[4] E. M. Tokit, H. A. Mohammed, and M. Z. Yusoff, "Thermal performance of optimized interrupted microchannel heat sink (MCHS) using nanofluids,” International Communications in Heat and Mass Transfer, vol. 39, pp. 1595-1604, 2012.

[5] E. B. Haghihi, M. Salemi, N. Nikkam, Z. Anwar, I. Lumbreras, M. Behi, S. A. Mirmohammadi, H. Poth, R. Khodabandeh, M. S. Toprak, M. Muhammed, B. Palm, “ Cooling performance of nanofluids in a small diameter tube,” Experimental Thermal and Fluid Science, vol. 49, pp. 114-122, 2013.

[6] M. R. Sohel, S. S. Khaleduzzaman, R. Saidur, A. Hepbasli, M. F. M. Sabri, and I. M. Mahbubul, "An experimentation investigation of heat transfer enhancement of a minichannel heat sink using $\mathrm{Al}_{2} \mathrm{O}_{3}-\mathrm{H}_{2}$ Onanofluid," International Journal of Heat and Fluid Flow, vol. 74, pp. 164-172, 2014.

[7] A. Ghadimi, R. Saidur, and H. S. C. Metselaar, "A review of nanofluid stability properties and characterization in stationary conditions,” International Journal of Heat and Mass Transfer, vol. 54, pp. 4051-4068, 2011.

[8] R. Saidur, K. Y. Leong, and H. A. Mohammad, “A review on applications and challenges of nanofluids,” Renewable and Sustainable Energy Reviews, vol. 15(3), pp. 1646-1668, 2011. 
[9] I. Zakaria, W. A. N. W. Mohamed, A. M. I Mamat, R. Saidur, W. H. Azmi, R. Mamat, K. I. Sainan, and H. Ismail, "Thermal analysis of heat transfer enhancement and fluid flow for low concentration of AL2O3 water-ethylene glycol mixture nanofluid in a single PEMFC cooling plate,” Energy Procedia, vol. 79, pp. 259-264, 2015.

[10] M. K. Moraveji, R. M. Ardehali, and A. Ijam, "CFD investigation of nanofluid effects (cooling performance and pressure drop) in mini-channel heat sink,” International Communications in Heat and Mass Transfer, vol. 40, pp. 58-66, 2013.

[11] Y.T. Yang, K.T Tsai, Y. H. Wang, and S. H. Lin, "Numerical study of microchannel heat sinperformance using nanofluids," International Communications in Heat and Mass Transfer, vol. 57, pp. 27-35, 2014.

[12] T. L. Bergman, A. S. Lavine, F.P. Incropera, and D. P. Dewitt, "Fundamentals of heat and mass transfer $\left(7^{\text {th }}\right.$ Edition)," John Wiley \& Sons, USA, pp. 995-1010, 2011.

[13] S. S. Khaleduzzaman, R. Saidur, J. Selvaraj, I. M. Mahbubul, M. R. Sohel, and I. M. Shahrul, "Nanofluids for thermal performance improvement in cooling of electronic device,” In Advanced Materials Research, Vol. 832, pp. 218-223, 2014.

[14] A. K. O Albdoor, "Numerical Investigation of Laminar Nanofluid Flow in Micro Channel Heat Sinks," Southern Technical University, Al-Nassiriah Technical Institute, Department of Mechanical Techniques, ThiQar, Iraq. International Journal of Mechanical Engineering and Technology (IJMET), vol. 5, Issue 12, pp. 86-96, December 2014.

[15] E. Farsad, S. P. Abbasi, M. S. Zabihi, and J. Sabbaghzadeh, "Numerical simulation of heat transfer in a micro channel heat sinks using nanofluids," Heat and Mass Transfer, vol. 47(4), pp. 479-490, 2011.

[16] Y.Xuan and W. Roetzel, "Conceptions for heat transfer correlation of nanofluids.” International Journal of heat and Mass transfer, vol.43 (19), pp.3701-3707, 2000.

[17] A. Ijam,and R. Saidur, "Nanofluid as a coolant for electronic devices (cooling of electronic devices)," Applied Thermal Engineering, vol. 32(2012), pp. 76-82, 2012.

[18] T. Bello-Ochende, L. Liebenberg, and J. P. Meyer, “Constructal cooling channels for micro-channel heat sinks,"International Journal of Heat and Mass Transfer, vol. 50(21-22), pp. 4141-4150,2007.

[19] X. L. Xie, Z. J. Liu, Y. L. He, and W. Q. Tao, "Numerical study of laminar heat transfer and pressure drop characteristics in a watercooled minichannel heat sink,” Applied Thermal Engineering, vol. 29(1), 64-74, 2009.

[20] W. Escher, T. Brunschwiler, N. Shalkevich, A. Shalkevich, T. Burgi, B. Michel, and D. Poulikakos, "On the Cooling of Electronics With Nanofluids,”Journal of Heat Transfer, 133(5), 2011.

[21] W. Q. Tao, Y. P. Cheng, and T. S. Lee," The Influence of Strip Location on the Pressure Drop and Heat Transfer Performance of a Slotted Fin,” Numerical Heat Transfer, Part a: Applications, vol. 52(5), pp. 463-480, 2007.

\section{AUTHOR PROFILE}

Siti Natasha Malik Fesalreceived the Bachelor degree and Masterin Mechanical Engineering from UniversitiTun Hussein Onn, Bt.Pahat,Johor in 2004 and 2015, respectively. Currently she is working as lecturer at Mechanical Department, Polytechnic UngkuOmar, Ipoh, Perak.

SitiSyazwanillminreceived the Bachelor degree in Applied Science of Maritime Technology from Universiti Malaysia Terengganu, Kuala Terenganu, Terenganu in 2010 and Masterin Mechanical Engineering from University Tun Hussein Onn,Bt.Pahat,Johor in 2015. Currently she is working as lecturer at Mathematics Science and Computer Department, Polytechnic UngkuOmar, Ipoh, Perak

ZurainiGanireceived the Bachelor degree in Mechatronic from KolejUniversitiTun Hussein Onn (KuiTTHO), Bt.Pahat, Johor in 2002 and Master in Mechanical Engineering from Universiti Kebangsaan Malaysia, Bangi, Selangor in 2010. Currently she is pursuing post-graduate studiesat Mechanical Engineering Department, University Kebangsaan Malaysia,Bangi,Selangor. 